\title{
Análises de óbitos relacionados a afogamentos em cinco municípios do estado do Rio de Janeiro
}

\author{
Analysis of fatalities by drowning in five Rio de Janeiro state's municipality \\ Análisis de muertes por ahogamiento en cinco condados del estado de Río de Janeiro \\ Paulo Queiroz Trinta ${ }^{1,2 \star}$, Regina Fernandes Flauzino.
}

\begin{abstract}
RESUMO
Objetivo: Analisar óbitos por afogamento no Estado do Rio de Janeiro, de municípios que possuam características físico-sociais diferentes entre si, a fim de propor modelos de intervenções personalizadas. Métodos: Dividiu-se entre interior/metóropole; e subdividiu-se entre serana/plana/litorânea e alta/média/baixa população absoluta. Analisaram-se os óbitos relacionados a afogamento, através do DATASUS, na categoria CID-10 entre 2007 e 2016. Resultados: As cidades escolhidas apresentaram porcentagem relacionada ao número total dos 258 óbitos, Niterói-102(39,5\%), Maricá-65(25,2\%), Três Rios-49(19\%), Nova Friburgo$27(10,4 \%)$ e Guapimirim-15(5,8\%). Óbitos em águas naturais (W-69) chegaram a 120(46,7\%) e óbitos não especificados (W-74) atingiram 107(41\%). Municípios receptores obtiveram a seguinte porcentagem de turistas em seus óbitos: Guapimirim-46,6\%, Maricá-53,8\% e Niterói-28,4\%. O município de Nova Friburgo foi considerado provedor com $25 \%$ dos óbitos em outras cidades. Conclusão: Demonstrou-se que nos litorâneos, metrópole ou interior, Niterói e Maricá, os óbitos ocorrem frequentemente com turistas nas praias, necessitando de medidas de prevenção reativa. Outros municípios do interior, serranos ou planos, Nova Friburgo, Três Rios e Guapimirim, com estatísticas de óbitos em rios, lagoas e cachoeiras, onde a presença do guarda-vidas é uma impossibilidade, as alternativas são as medidas de educação à população e a prevenção ativa, como sinalizações de perigos e avisos locais.
\end{abstract}

Palavras-chave: Afogamento, Morte, Prevenção.

\begin{abstract}
Objective: To analyze drowning deaths in the State of Rio de Janeiro, in municipalities that have different physical-social characteristics, in order to propose personalized intervention models. Methods: It was divided between interior/metropole; subdivided between mountaintown/plan/coastal and high/medium/low absolute population. Drowning-related deaths were analyzed using DATASUS, in the ICD-10 category between 2007 and 2016. Results: The chosen cities presented a percentage related to the total number of 258 deaths, Niterói-102(39.5\%), Maricá- 65(25.2\%), Três Rios-49(19\%), Nova Friburgo-27(10.4\%) and Guapimirim15(5.8\%). Deaths in natural waters (W-69) reached 120(46.7\%) and unspecified deaths (W-74) reached $107(41 \%)$. receptor municipalities obtained the following percentage of tourists in their deaths: Guapimirim46.6\%, Maricá-53.8\% and Niterói-28.4\%. The municipality of Nova Friburgo was considered PROVIDER with $25 \%$ of deaths in other cities. Conclusion: It has been shown that in coastal areas, metropolis or interior, Niterói and Maricá, deaths occur frequently with tourists at the beaches, requiring reactive prevention measures. Other municipalities in the interior, mountain-town or plan, Nova Friburgo, Três Rios and Guapimirim, with statistics of deaths in rivers, lagoons and waterfalls, where the presence of the lifeguard is an impossibility, the alternatives are the measures of education to the population and the active prevention, such as hazard signs and local warnings.
\end{abstract}

Keywords: Drowning, Death, Prevention.

1 Universidade Federal Fluminense (UFF), Niterói - Rio de Janeiro. *E-mail: trinta.defesacivil@gmail.com

2 Secretaria de Estado de Defesa Civil (SEDEC), Rio de Janeiro.

SUBMETIDO EM: 1/2020

ACEITO EM: 2/2020

PUBLICADO EM: 4/2020

REAS/EJCH | Vol.12(6) | e3038 | DOI: https://doi.org/10.25248/reas.e3038.2020 Página 1 de 9 


\section{RESUMEN}

Objetivo: analizar las muertes por ahogamiento en el estado de Río de Janeiro, en municipios que tienen diferentes características físicas-sociales, para proponer modelos de intervención personalizados. Métodos: se dividió entre interior/metrópolis; se subdividió entre serana/plana/litorânea y alta/media /baja población absoluta. Las muertes relacionadas con ahogamientos se analizaron utilizando DATASUS, en la categoría CIE-10 entre 2007 y 2016. Resultados: Las ciudades elegidas presentaron un porcentaje relacionado con el número total de 258 muertes, Niterói-102(39.5\%), Maricá-65(25.2\%), Três Rios-49(19\%), Nova Friburgo$27(10.4 \%)$ y Guapimirim-15(5.8\%). Las muertes en aguas naturales (W-69) alcanzaron $120(46.7 \%)$ y las muertes no especificadas (W-74) alcanzaron 107(41\%). Los municipios receptores obtuvieron el siguiente porcentaje de turistas en sus muertes: Guapimirim-46.6\%, Maricá-53.8\% y Niterói-28.4\%. El municipio de Nova Friburgo fue considerado provedor con el $25 \%$ de las muertes en otras ciudades. Conclusión: se ha demostrado que en las zonas costeras, metrópolis o interior, Niterói y Maricá, las muertes ocurren con frecuencia con los turistas en las playas, lo que requiere medidas de prevención reactivas. Otros municipios del interior, serrano o plano, Nova Friburgo, Três Rios y Guapimirim, con estadísticas de muertes en ríos, lagunas y cascadas, donde la presencia del socorrista es imposible, las alternativas son las medidas de educación a la población y la prevención activa, como señales de peligro y advertencias locales.

Palabras clave: Ahogamiento, Muerte, Prevención.

\section{INTRODUÇÃO}

O afogamento caracteriza-se pela asfixia por submersão ou imersão em meio líquido, através da entrada desse líquido pelas vias respiratórias e impossibilitando, de forma completa ou parcial, a respiração e consequentemente a troca gasosa (SZPILMAN D, 2000). É responsável pela morte de uma pessoa a cada 1,5 segundos de acordo com o Relatório Global sobre Afogamentos de 2014 da Organização Mundial de Saúde (OMS).

Segundo o Boletim Brasil de Afogamentos 2018 da Sociedade Brasileira de Salvamento Aquático (SOBRASA) o afogamento figura entre as cinco maiores causas de óbito de 1 a 29 anos no Brasil, diminuindo sua incidência conforme a maturação da idade, mas ainda tendo grande relevância em valores de vidas perdidas de crianças, jovens e adultos em plena fase produtiva.

Estima-se que algumas ferramentas possam interferir diretamente nesse cenário pois, através de atividades aquáticas na Educação Física pode-se potencializar e desenvolver os conhecimentos de crianças (faixa etária abordada no estudo), conscientizar a importância da prevenção e impactar a sociedade de maneira geral (TORRES RA, 2019).

Conforme o Boletim de Afogamentos SOBRASA de 2018, quando se compara as principais causas de óbitos entre um e vinte e nove anos de idade, o afogamento é a segunda maior causa de óbitos de crianças de um a nove anos, persistindo nas estatísticas na terceira posição entre crianças de dez a quatorze anos.

Abrange também duas subdivisões de idades de quinze a dezenove e de vinte a vinte quatro anos em quarto lugar. Na faixa etária compreendida entre vinte cinco e vinte nove anos, o afogamento ocupa a quinta posição como maior causa de óbitos.

Szpilman D. (2018) afirma que diariamente presencia-se o impacto de notícias de pessoas que se envolveram de alguma forma em algum tipo de incidente em meio aquático pois através do sítio "Google News" são reportadas pelo menos 3 tragédias por dia no Brasil, revelando apenas uma pequena parte do problema afogamento. Geralmente é relatada a história de um brasileiro saudável com o destino trágico de uma morte precoce, onde a família teve seu ente querido arrancado do convívio por esse desastre que poderia ser evitado.

Esse estudo tem como objetivo analisar os óbitos por afogamento em municípios do Estado do Rio de Janeiro, que possuam características físico-sociais diferentes entre si, a fim de propor modelos de intervenções personalizadas para redução desse desastre. 


\section{MÉTODOS}

O estudo de caso avaliou dados de forma quantitativa, sem a necessidade de comitê de ética por se tratarem de dados secundários disponíveis em sítios públicos e de livre acesso. No intuito de caracterizar municípios específicos que pudessem representar diferenças entre si e similaridades com outros não elencados no estudo, definiu-se anteriormente Niterói pela característica de ser a segunda metrópole litorânea mais populosa do estado do Rio de Janeiro (IBGE, 2010); Maricá por ser uma cidade de interior, vizinha dessa metrópole, com a mesma sequência de litoral que Niterói; Nova Friburgo por ter sido palco de um dos maiores desastres hidrológicos do país (RODRIGUES CA, et al., 2014); Três Rios por ser um município com importante área fluvial e que possui o encontro de três rios em sua área; e Guapimirim por ser um município limítrofe à Bacia Hidrográfica da Baía de Guanabara de acordo com Plano Estadual de Recursos Hídricos do Estado do Rio de Janeiro (2014), caracterizado por eventos de enxurradas em cachoeiras, que popularmente são chamados de cabeça d'água.

As cidades foram divididas primeiramente em dois grupos sendo eles METRÓPOLE e INTERIOR. Metrópole sendo considerada como uma cidade de elevado desenvolvimento urbano e econômico, concentrando empregos, serviços e uma relação de dependência com municípios vizinhos desprovidos da mesma densidade urbana (PENA RFA, 2019). Os municípios que não se encaixavam na categoria supracitada foram classificados como INTERIOR.

A diferenciação entre SERRANA, LITORÂNEA e PLANA deu-se pela altitude média, onde cidades acima de $200 \mathrm{~m}$ acima do nível do mar foram caracterizadas como SERRANAS. LITORÂNEAS foram aquelas com médias menores do que $200 \mathrm{~m}$ acima do nível do mar e banhadas por oceano. PLANAS foram aquelas que estão abaixo de $200 \mathrm{~m}$ de altitude média acima do nível do mar, sem ser banhada por oceano.

As cidades foram ainda divididas pela população absoluta do município, em ALTA, MÉDIA e BAIXA, sendo classificadas como ALTAS as com mais de 500.000 habitantes; MÉDIAS as com mais de 150.000 habitantes, como BAIXA, as com menos de 150.000 habitantes.

Não foram estudados os dados em forma de densidade demográfica por considerar que tal medida mensura a quantidade de habitantes por $\mathrm{m}^{2}$, o que não tem relevância na possibilidade de ocorrência de afogamento, necessitando sim de corpos hídricos, naturais ou não, para que aconteça o óbito estudado.

O foco do trabalho busca a amplitude total do número de pessoas que podem vir a óbito por afogamento nos municípios avaliados logo, a população absoluta é um dado importante, pois indica o espaço amostral do número de pessoas que, sendo caracterizadas por população fixa, estão suscetíveis ao risco abordado. Em cidades de veraneio, onde pessoas costumam passar férias, feriados e dias de folga, esse número é acrescido de maneira sensível, possibilitando o aumento das estatísticas de óbito por afogamento.

Elaborou-se um banco de dados através do uso do software on-line "Tabwin" do DATASUS, Ministério da Saúde, acessados em 2018. A frequência absoluta dos números de óbitos por afogamento nos municípios compusera a tabela. O número de residentes dos municípios que vieram a óbito por afogamento também fora elencado, todos do período de janeiro de 2007 a dezembro de 2016. Os dados foram selecionados usando as "Categorias CID-10", sob os códigos: V-90 - Acidente com embarcação causando afogamento submersão; V-92 - Afogamento submersão relacionados a transporte pela água sem acidente com a embarcação; W-65 - Afogamento submersão durante banho banheira; W-66 - Afogamento submersão consecutiva à queda dentro de uma banheira; W-67 - Afogamento e submersão em piscina; W-68 - Afogamento submersão por consequentes a queda dentro de uma piscina; W-69 - Afogamento e submersão em águas naturais; W-70 Afogamento submersão consequentes à queda dentro de águas naturais; W-73 - Outros afogamentos e submersões especificados; W-74 - Afogamento e submersão. Não Especificados; X-71 - Lesão autoprovocada intencionalmente por afogamento e submersão; X-92 - Agressão por meio de afogamento e submersão; e Y-21 - Afogamento e submersão, intenção não determinada.

Foi realizado levantamento conceitual através de documentos, artigos, periódicos, manuais e capítulos de livros que discorrem sobre óbitos relacionados com afogamentos em diversas localidades do Estado do Rio de Janeiro, do Brasil e do Mundo, possibilitando assim análises mais criteriosas dos dados. 
Pesquisou-se sobre as características, os recursos diversos, as peculiaridades físico-sociais, dentre outros aspectos que possam ser um interveniente na redução das vulnerabilidades e consequentemente dos óbitos por afogamentos.

\section{RESULTADOS}

Dentre as cidades que foram selecionadas e posteriormente divididas entre dois grupos, sendo eles METRÓPOLE e INTERIOR, Niterói foi a única alocada no grupo de METRÓPOLE enquanto Maricá, Nova Friburgo, Três Rios e Guapimirim foram alocadas no grupo de INTERIOR.

A classificação entre SERRANA, LITORÂNEA e PLANA deu-se pela altitude média, onde cidades acima de $200 \mathrm{~m}$ acima do nível do mar foram caracterizadas como SERRANAS, sendo elas Nova Friburgo com 846m e Três Rios com 275m; LITORÂNEAS foram aquelas com médias menores do que $200 \mathrm{~m}$ acima do nível do mar, banhadas por oceano, sendo essas Niterói com $2 \mathrm{~m}$ e Maricá com $6 \mathrm{~m}$; e PLANAS foram consideradas aquelas que estão abaixo de $200 \mathrm{~m}$ de altitude média do nível do mar, sem ser banhada por oceano, que é o caso de Guapimirim com 49m.

A outra subdivisão caracteriza-se pela população absoluta do município, especificamente entre ALTA, MÉDIA e BAIXA, classificando como MÉDIA Niterói com 497.883 habitantes e Nova Friburgo com 185.102 habitantes; como BAIXA foram classificadas Maricá com 149.876 habitantes, Três Rios com 79.230 habitantes e Guapimirim com 57.105 habitantes, todas do ano de 2016.

Ao analisar os planos de contingência e demais informações dos municípios, constata-se que Niterói, além de ser uma cidade litorânea, foi caracterizada com média população absoluta, além de apresentar mais recursos para resposta aos afogamentos, contribuindo para uma melhor primeira resposta e consequentemente menor vulnerabilidade.

Maricá também é uma cidade litorânea, mas com uma baixa população absoluta e menor quantidade de recursos operacionais destinados para prevenção e resposta aos afogamentos do que sua cidade vizinha supracitada.

Três Rios foi selecionada por ser uma cidade interiorana e pela grande malha pluvial em sua área. Nova Friburgo é um município localizado em região serrana, apresentando especificidades por conta de desastres hidrológicos. Guapimirim localiza-se de forma limítrofe dentro de uma bacia hidrográfica, próximo ao nível do mar, evidenciando suas peculiaridades de afogamentos em rios, cachoeiras e em fenômenos de enxurradas como cabeça d’água.

Os números de óbitos de afogamentos são oriundos do banco de dados do Ministério da Saúde, através do uso do software on-line "Tabwin" do DATASUS, acessados em 2018, distribuídos nos anos desde janeiro de 2007 a dezembro de 2016 em cada município (Tabela 1):

Tabela 1 - Número de óbitos por afogamento por ano nos municípios.

\begin{tabular}{crrrrrrrrrrr}
\hline Município & 2007 & 2008 & 2009 & 2010 & 2011 & 2012 & $\mathbf{2 0 1 3}$ & $\mathbf{2 0 1 4}$ & $\mathbf{2 0 1 5}$ & $\mathbf{2 0 1 6}$ & Total \\
\hline Guapimirim & 2 & 2 & 4 & 1 & 1 & 1 & 1 & 1 & 2 & - & 15 \\
Maricá & 9 & 6 & 6 & 5 & 5 & 5 & 9 & 11 & 1 & 8 & 65 \\
Niterói & 15 & 12 & 11 & 8 & 6 & 9 & 15 & 13 & 10 & 3 & 102 \\
Nova Friburgo & 2 & 1 & 3 & 8 & 1 & 3 & 3 & 4 & 1 & 1 & 27 \\
Três Rios & 4 & 5 & 2 & 3 & 7 & 10 & 8 & 4 & 3 & 3 & 49 \\
\hline
\end{tabular}

Fonte: MS/SVS/CGIAE - Sistema de Informações sobre Mortalidade - SIM (2018). 
As cinco cidades apresentaram a seguinte porcentagem relacionada ao número total dos 258 óbitos, Niterói - 102 (39,5\%), Maricá - 65 (25,2\%), Três Rios - 49 (19\%), Nova Friburgo - 27 (10,4\%) e Guapimirim - 15 (5,8\%). Óbitos em águas naturais (W-69) chegaram a 120 (46,7\%) e óbitos não especificados (W-74) atingiram 107 (41\%).

As médias das taxas de óbitos por afogamento por 100.000 habitantes durante o período estudado foram: Niterói - 1,32; Maricá - 5,61; Três Rios 6,28; Nova Friburgo - 5,6; e Guapimirim - 2,92 (Tabela 2).

Tabela 2 - Categorias CID-10 - óbitos por afogamento entre 2007 e 2016.

\begin{tabular}{|c|c|c|c|c|c|c|}
\hline & Niterói & Maricá & Nova Friburgo & Três Rios & Guapimirim & Total \\
\hline V90 & 0 & 1 & 0 & 1 & 0 & 2 \\
\hline V92 & 0 & 0 & 0 & 0 & 0 & 0 \\
\hline W65 & 0 & 0 & 0 & 0 & 0 & 0 \\
\hline W66 & 0 & 0 & 0 & 0 & 0 & 0 \\
\hline W67 & 0 & 6 & 1 & 1 & 0 & 8 \\
\hline W68 & 1 & 0 & 1 & 0 & 0 & 2 \\
\hline W69 & 49 & 37 & 7 & 24 & 3 & 120 \\
\hline W70 & 0 & 0 & 3 & 2 & 0 & 5 \\
\hline W73 & 1 & 0 & 2 & 0 & 0 & 3 \\
\hline W74 & 49 & 21 & 12 & 13 & 12 & 107 \\
\hline$X 71$ & 1 & 0 & 1 & 7 & 0 & 9 \\
\hline$x 92$ & 1 & 0 & 0 & 1 & 0 & 2 \\
\hline Y21 & 0 & 0 & 0 & 0 & 0 & 0 \\
\hline Total & 102 & 65 & 27 & 49 & 15 & 258 \\
\hline
\end{tabular}

Fonte: MS/SVS/CGIAE - Sistema de Informações sobre Mortalidade - SIM (2018).

O Tabela 3 apresenta os dados de óbitos por afogamento por município (local de ocorrência), bem como os óbitos de residentes (vítimas que possuíam residência naquele município) do respectivo município que vieram a falecer por afogamento, mas que não vieram a óbito naquela cidade.

Tabela 3 - Análise da diferença de óbitos por ocorrência por óbitos por residência (residentes do município) entre 2007 e 2016.

\begin{tabular}{cccc}
\hline Município & Ocorrência & Residência & Diferença \\
\hline Guapimirim & 15 & 8 & 7 \\
Maricá & 65 & 30 & 35 \\
Niterói & 102 & 73 & 29 \\
Nova Friburgo & 27 & 36 & -9 \\
Três Rios & 49 & 45 & 4 \\
Total & 258 & 192 & 66 \\
\hline
\end{tabular}

Fonte: MS/SVS/CGIAE - Sistema de Informações sobre Mortalidade - SIM (2018).

\section{DISCUSSÃO}

De acordo com o Tabela 1, os dois municípios litorâneos (Niterói e Maricá) totalizaram $64,7 \%$ dos 258 óbitos, seguido de Três Rios com $19 \%$ dos óbitos e que possui uma grande área fluvial. O município serrano de Nova Friburgo ficou com 10,4\% dos óbitos seguido de Guapimirim com 5,8\%.

Percebe-se no Tabela 2, onde 107 óbitos são enquadrados na categoria W-74 afogamento e submersão não especificados, representando $41,4 \%$ do total de 258 óbitos analisados. Estima-se que, além dos apontados da categoria W-74, 94\% da informação dos incidentes aquáticos no Brasil não são conhecidos, 
pois os casos relacionados aos óbitos e internações hospitalares só são computados como afogamento quando geram atendimento com internação hospitalar (SOBRASA, 2018).

Segundo o Manual de Capacitação Básica em Defesa Civil de 2014, a Classificação e Codificação Brasileiras de Desastres (COBRADE) se adequou ao Banco de Dados Internacional de Desastres, do Centro para Pesquisa sobre Epidemiologia de Desastres (CRED), da Organização Mundial de Saúde da Organização das Nações Unidas (OMS/ONU). Essa necessidade de adequação às terminologias internacionais possibilitou a evolução de conceituações nacionais e a tipificação de 82 desastres.

Alguns deles têm no seu mecanismo do trauma o afogamento, mas seu óbito é registrado no COBRADE como vítimas de outros desastres como terremotos, inundações, enxurradas, alagamentos, ressacas, transportes marítimos ou aquaviário. É possível que não compreendamos a dimensão do problema por conta de estatísticas subnotificadas e alocadas em outras categorias que não a do afogamento.

Analisando ainda a computação do óbito por afogamento como desastre natural, e não como afogamento específico, o desastre de 2011 de Nova Friburgo vem corroborar hipoteticamente que as mortes não são devidamente classificadas de acordo com o seu respectivo mecanismo do trauma, mascarando uma realidade e dificultando uma possível intervenção mais precisa.

Observa-se que no ano de 2011 (Tabela 1) do supracitado desastre hidrológico, apenas uma morte foi atribuída a afogamento na categoria W-74 (afogamento e submersão não especificados), corroborando o fato de estatísticas reprimidas de óbitos por afogamento que, provavelmente aconteceram, mas não foram computados como tal.

Estudos acadêmicos compilados no Boletim Brasil de Afogamentos da SOBRASA mostram que os principais fatores de riscos como o uso de bebidas alcoólicas, baixa educação, comportamento de risco, falta de supervisão e alguns tipos de doenças específicas, contribuem para esse quadro. Demonstram também que o afogamento não é um simples acidente, não acontece por acaso, tem prevenção, e esta é a melhor forma de tratamento (SZPILMAN D, 2010).

A percepção de risco é um dos fatores fundamentais na redução dos óbitos por afogamento. Como por exemplo, anualmente na Austrália são recebidos mais de trezentos milhões de visitantes, com variadas percepções de risco de afogamentos devido a culturas heterogêneas.

Tal fato fez com que Lawes J, et al. (2019), elaborasse uma pesquisa para entender como os frequentadores analisavam os riscos da costa e percebeu que $45 \%$ se consideravam maus nadadores e que $64 \%$ não conseguiriam se deslocar por 50 metros no mar sem ter que parar. Percebeu-se também que ao ponderar o quão segura é uma atividade em vez de perigosa, a percepção do risco aumenta em média 9\%, mas que superestimam os riscos mais baixos, provavelmente por conta de conceitos errôneos.

Dentro da categoria W-69, algumas das suas subdivisões não auxiliam totalmente na correta especificidade do dado, pois cada localidade necessita de prevenção de acordo com seu risco. O uso de forma aleatória da terminologia de "afogamento não fatal" também contribui para mascarar o fardo total que o afogamento representa para as estatísticas, dificultando estudos por falta de dados fidedignos (MEDDINGS D, et al., 2019). Aclarando tal fato, ressalta-se ainda a necessidade de uma melhor especificação e subdivisão da categoria CID W-69 - afogamento e submersão em águas naturais.

Essa categoria abrange os óbitos em W 69.0 - Afogamento e submersão em águas naturais residência; W 69.1 - Afogamento e submersão em águas naturais habitação coletiva; W 69.2 - Afogamento e submersão em águas naturais escolas, outras instituições e áreas de administração pública; W 69.3 - Afogamento e submersão em águas naturais área para a prática de esportes e atletismo; W 69.4 - Afogamento e submersão em águas naturais rua e estrada; W 69.5 - Afogamento e submersão em águas naturais áreas de comércio e de serviço; W 69.6 - Afogamento e submersão em águas naturais áreas industriais e em construção; W 69.7 - Afogamento e submersão em águas naturais fazenda; W 69.8 - Afogamento e submersão em águas naturais outros locais especificados; e W 69.9 - Afogamento e submersão em águas naturais local não especificado. É de extrema importância para a escolha dos métodos preventivos a precisão do real local onde aconteceu o óbito, diferenciando-os entre praias, rios, lagos, represas e outras áreas que apresentam peculiaridades diferentes em seus riscos e consequentemente em suas medidas preventivas. 
Ao verificar as informações da análise da diferença de óbitos por ocorrência por óbitos por residência (Tabela 3), onde temos na $3^{\underline{a}}$ coluna a "Diferença" da $1^{\text {a }}$ coluna "Ocorrência" pela $2^{a}$ coluna "Residência", encontra-se o número de pessoas que vieram a óbito naquele município, mas que não são residentes.

Nos municípios de Niterói, Maricá, Três Rios e Guapimirim encontra-se um resultado numérico positivo, demonstrando que eles recebem um afluxo de turistas que vêm a óbito por afogamento em seu município, caracterizando-os como RECEPTORES de óbitos por afogamento. Entretanto, Nova Friburgo apresenta um número negativo (-9), demonstrando que seus munícipes estão morrendo afogados em outras cidades, caracterizando-o como PROVEDOR de óbito por afogamentos (TRINTA PQ et al., 2018).

Baseado nessa premissa pode-se considerar que os percentuais de turistas que vêm a óbito por afogamento em Guapimirim são de 46,6\%, em Maricá 53,8\% e em Niterói 28,4\%, caracterizando-os como municípios receptores de óbitos por afogamento.

Já em Nova Friburgo, 25\% dos óbitos dos residentes foram em outro município, o que nos permite supor que Nova Friburgo é um município provedor de óbitos por afogamento. Em Três Rios 91,8\% dos óbitos no município são dos próprios munícipes residentes.

Para todos os municípios, seria recomendável a adesão ao Programa Município + Resiliente ao Afogamento da SOBRASA, visto que o mesmo aborda atitudes simples e comprometimento do poder público. Para cada peculiaridade de maior incidência de óbito por determinado afogamento, são recomendados programas distintos da SOBRASA.

Entretanto, se faz necessária a compreensão de que os afogamentos não reduzirão somente pela ação de uma única instituição, pois deve-se contar com a participação de escolas, igrejas, pastores, e até mesmo curandeiros de tribos para devida disseminação nas comunidades (MOKALA MT, 2019)

No município de Niterói, tendo as maiores causas de óbitos os afogamentos por submersão em águas naturais (W-69) e afogamento e submersão não especificados (W-74), com 49 ocorrências cada um, pressupondo que a maioria dessas águas naturais sejam no mar aberto (praias) e que seu público mais recorrente nas estatísticas de óbitos venham a ser turistas, recomenda-se: "Programa Kim na Escola" (também incentivado em municípios provedores de óbitos por afogamento), "Dicas Praia + Segura" (em ônibus oriundos de diversas localidades que venham convergir em locais de praia), "Dicas e Programa Surf Salva" (para surfistas das localidades próximas), "Dicas Mergulho + Seguro", "Esporte Lifesaving" e"Lifesaving Club".

No município de Maricá, tendo as maiores causas de óbitos os afogamentos por submersão em águas naturais (W-69) totalizando 37 óbitos, pressupondo que a maioria dessas águas naturais sejam no mar aberto (praias) ou em alguma das sete lagoas, que seu público mais recorrente nas estatísticas de óbitos venham a ser turistas, recomenda-se: a continuidade do "Projeto Onda Certa nas Escolas" (também incentivado em municípios provedores de óbitos por afogamento), "Dicas Praia + Segura" (em ônibus oriundos de diversas localidades que venham convergir em locais de praia), "Dicas Navegue + Seguro","Dicas e Programa Surf Salva" (para surfistas das localidades próximas), "Dicas Mergulho + Seguro", "Esporte Lifesaving" e "Lifesaving Club".

No município de Três Rios, tendo as maiores causas de óbitos os afogamentos por submersão em águas naturais (W-69) totalizando 24 óbitos, pressupondo que a maioria dessas águas naturais sejam nos rios, que seu público mais recorrente nas estatísticas de óbitos venha a ser residentes, recomenda-se: "Dicas Navegue + Seguro", "Programa Kim na Escola", "Dicas Rios + Seguros" e "Programa Inundações".

Óbitos por afogamentos que são oriundos de embarcações nos rios também impactam mais de cinquenta mil canadenses (durante um período de vinte anos), ocorrendo na sua maioria com homens entre quinze e setenta e quatro anos (SHENDELMAN E et al., 2019).

No município de Nova Friburgo, tendo as maiores causas de óbitos os afogamento e submersão não especificados (W-74) totalizando 12 óbitos, e como $2^{\mathrm{a}}$ maior causa os Afogamentos por submersão em águas naturais (W-69), pressupondo que a maioria dessas águas naturais sejam nos rios e nas cachoeiras, que seu público mais recorrente nas estatísticas de óbitos venham a ser residentes, recomenda-se: "Programa Kim na Escola", "Dicas Rios + Seguros"(ressaltando informações para residentes que vão fazer turismo em outros 
locais) e Programa Inundações. Nas cidades do interior da Austrália também reside uma maior dificuldade em levar informações e campanhas de prevenção para áreas rurais com comunidades mais espaçadas e distantes, aumentando as estatísticas com óbitos por afogamentos oriundos de embarcações (FRANKLIN R et al., 2019).

No município de Guapimirim, tendo as maiores causas de óbitos os Afogamento e submersão não especificados (W-74) totalizando 12 óbitos, e como $2^{2}$ maior causa os afogamentos por submersão em águas naturais (W-69) com 3 ocorrências, pressupondo que a maioria dessas águas naturais sejam nos rios e cachoeiras, que seu público mais recorrente nas estatísticas de óbitos venham a ser turistas (46,6\%), recomenda-se: "Programa Kim na Escola", "Dicas Rios + Seguros" e "Programa Inundações" (ressaltando informações para turistas sobre enxurradas, conhecida popularmente como "Cabeça D’água").

\section{CONCLUSÃO}

A heterogeneidade entre os municípios, por poucas variáveis analisadas, reforça que o afogamento deve ter customização no seu combate. Se for possível classificar um município pelos fatores de risco através de dados mais fidedignos, talvez possamos sugerir receitas de intervenções mais efetivas, concluindo que nos litorâneos, com média ou baixa população absoluta, os óbitos ocorrem mais com turistas nas praias, necessitando de medidas de prevenção reativa (como a presença mais ostensiva de guarda-vidas); nos serranos e planos, de média ou baixa população absoluta, com estatísticas de óbitos de seus residentes em rios, lagoas e cachoeiras, onde a presença do guarda-vidas é uma impossibilidade, as alternativas são as medidas de educação à população e prevenção ativa como, sinalizações de perigos e avisos locais.

\section{REFERÊNCIAS}

1. BRASIL. Governo Federal. In: Lei n. 12.608, de 10 de abril de 2012. Política Nacional de Proteção e Defesa Civil. Disponível em: http://www.planalto.gov.br/ccivil_03/_Ato2011-014/2012/Lei/L12608.htm.

Acesso em: 18 dez. 2018.

2. CANTWELL GP. Afogamento Apresentação Clínica. Medscape. Background. 2p. Junho de 2019.

3. CASTRO ALC. Glossário de Defesa Civil Estudos de Riscos e Medicina de Desastres. Ministério da Integração Nacional 5a edição. Brasília, 2017; p12.

4. FRANKLIN R, et al. Afogamento Rural na Austrália. Conferência Mundial para Prevenção do Afogamento - Abstract book, p.33. Disponível em: www.ilsf.org.

5. INSTITUTO BRASILEIRO DE GEOGRAFIA E ESTATÍSTICA. Censo Demográfico. Disponível em: https://www.ibge.gov.br/estatisticas-novoportal/sociais/saude/9662-censo-demografico-2010.html?=\&t=0-que-e. Acesso em: 17 dez. 2018.

6. INSTITUTO ESTADUAL DAS ÁGUAS. Plano Estadual de Recursos Hídricos do Estado do Rio de Janeiro, 2014. Disponível em:

http://www.inea.rj.gov.br/cs/groups/public/documents/document/zwew/mdcx/ edisp/inea0071539.pdf Acesso em: 06 ago. 2019.

7. MEDDINGS D, et al. Clarificação e categorização do afogamento não fatal. Conferência Mundial para Prevenção do Afogamento - Abstract book, p.27. Disponível em: www.ilsf.org.

8. MOKALA MT. Identificando intervenientes da comunidade para prevenção do afogamento. Conferência Mundial para Prevenção do Afogamento - Abstract book, p.223. Disponível em: www.ilsf.org.

9. MINISTÉRIO DA INTEGRAÇÃO NACIONAL. Secretaria Nacional de Proteção e Defesa. Módulo de formação: noções básicas em proteção e defesa civil e em gestão de riscos, 2017. Brasília: 2017; p 23.

10. MINISTÉRIO DA SAÚDE. Portal de Saúde SUS. Informações de Saúde (TABNET). Afogamento e submersão em águas naturais. 2019. In: Banco de Saúde. Disponível em:

11. http://cid10.bancodesaude.com.br/cid-10-w/w69/afogamento-e-submersao-em-aguas-naturais. Acesso em: 26 mai. 2019.

12. MINISTÉRIO DA SAÚDE. Portal de Saúde SUS. Informações de Saúde (TABNET) Demográficas e Socioeconômicas. Disponível em: http://tabnet.datasus.gov.br/cgi/tabcgi.exe?ibge/cnv/poptrj.def. Acesso em 25 set. 2018.

13. PENA RFA. "O que é Metrópole?". Brasil Escola. Disponível em:

14. https://brasilescola.uol.com.br/o-que-e/geografia/o-que-e-metropole.htm. Acesso em: 1 jun. 2019.

15. PRÉ-HOSPITALAR TRAUMA LIFE SUPORT. Atendimento pré-hospitalar ao traumatizado. PHTLS/NAEMT. $7^{\text {a }}$ ed. Impresso no Canadá: Elsevier, p. 525, 2011.

16. RODRIGUES CA, et al. Avaliação econômica dos casos de Dengue atribuídos ao desastre de 2011 em Nova Friburgo (RJ), Brasil. Ciênc. Rio de Janeiro. Saúde Coletiva, v.19, n.9, set. 2014. 
17. SOCIEDADE BRASILEIRA DE SALVAMENTO AQUÁTICO. 2018. In: Boletim Brasil de Afogamentos 2018. Disponível em: http://www.sobrasa.org/afogamento-boletim- epidemiologico-no-brasil-ano-2017-ano-base-de-dados2015-e-outros/. Acesso em: 25 set. 2019.

18. SHENDELMAN E, et al. Pesquisa e política de informação: o lugar de escopo de revisão da abordagem sistemática e metodologia estabelecida na pesquisa em prevenção de afogamentos. Conferência Mundial para Prevenção do Afogamento - Abstract book, p.29. Disponível em: www.ilsf.org.

19. SZPILMAN D. Afogamento - Boletim epidemiológico no Brasil. Sociedade Brasileira de Salvamento Aquático SOBRASA, 2017. Disponível em: http://www.sobrasa.org/?p=23335. Acesso em: 29 nov. 2019.

20. SZPILMAN D, et al. Afogamento. New England Journal of Medicine. Disponível em: <https://www.nejm.org/doi/full/10.1056/NEJMra1013317>. Acesso em: 10 ago. 2019.

21. TORRES RA. A EDUCAÇÃO FÍSICA NA ALFABETIZAÇÃO. Revista Artigos. Com, 7, e1743. Recuperado de https://www.acervomais.com.br/index.php/artigos/article/view/1743

22. TRINTA $P Q$, et al. Intervenção para redução nos óbitos por afogamentos de turistas no Estado do Rio de Janeiro: Seminário Nacional de Bombeiros. Foz de Iguaçu (PR), nov. 2018.

23. WORLD HEALTH ORGANIZATION. Global report on drowning: preventing a leading killer. WHO Library, 2014. 